Two other interesting results warrant special mention. First, the number of papers by trainees in London (42/149,28.2\%) when the trainee was first author was disproportionately large. This could either be because of the very large number of trainees in these training schemes or the greater emphasis and opportunities given to these trainees for involvement in research. Second, the type of original research conducted by trainees was noteworthy. The majority of the studies (83\%) involved no direct patient contact: questionnaire surveys, audits and case note-based studies predominated. This probably is a reflection of the practical difficulties that trainees encounter in getting involved in more 'original' research, such as lack of protected time for research, changing jobs every 6-12 months, inadequate support from trainers and bureaucracy of ethics applications, to list just a few.

Out of the 124 original studies, 17 (13.7\%) were audits. Audit is regarded as the cornerstone of clinical governance and, given its emphasis in the record of intraining assessment, it is surprising that relatively few audit papers were published by trainees. There could be two reasons: audits tend to be conducted 'centrally' within trusts (by the research and development department or the clinical governance team) and hence trainee input is limited; second, the Psychiatric Bulletin in recent years has increased its quality threshold for publication, and a full audit cycle is required before such papers can be accepted for publication. The length of training posts makes it unlikely that trainees will be involved in the full cycle.

Specialist registrars were first authors on only 124 papers over the 5-year study period (approximately 25 papers per annum). There are over 1500 SpRs in psychiatry in the UK, and even if only some contributed to the Bulletin, this number is still very small. This calls into question the issue of proper utilisation of the 'research day' by SpRs. Although most SpRs vehemently argue for its continuation (Vassilas et al, 2002), it is probably time to re-evaluate its usefulness and consider alternatives.

\section{Limitations}

This study had two important limitations. First, the study period of 5 years is relatively short. However, prior to 1999 the categories in the Psychiatric Bulletin under which papers were published were different from the current categories. Hence, inclusion of those papers would have rendered comparisons invalid. Second, although this study demonstrates that trainees contribute substantially to the Bulletin, it does not prove/disprove a possible bias against papers by trainees. There is no reason to suspect that this is the case and exploration of this methodologically complex issue was beyond the remit of this study.

\section{Conclusion}

In the light of the findings of this study, it seems reasonable to conclude that the Bulletin is indeed 'trainee-friendly'. The inclusion of a 'trainees section' in the Psychiatric Bulletin (as existed prior to 1999) might encourage trainees to publish more papers.

\section{Declaration of interest}

S.G. was the trainee editor of Psychiatric Bulletin and is now an editorial board member. F.O. is an editorial board member of Psychiatric Bulletin.

\section{References}

VASSILAS, C., TADROS, G. \& DAY, E. (2002) The research day: a suitable case for treatment? Psychiatric Bulletin, 26, 313-314. WILLIAMS, C. J. \& CURRAN, S. (1998) Research by senior registrars in psychiatry. Psychiatric Bulletin, 22, 102-104.

*Sanju George Specialist Registrar in General Adult Psychiatry, Queen Elizabeth Psychiatric Hospital, Edgbaston, Birmingham B15 2QZ, e-mail: sanju.george@ talk21.com, Ditesh Dhaya Senior House Officer in Psychiatry, Femi Oyebode Professor of Psychiatry and Consultant Psychiatrist, Queen Elizabeth Psychiatric Hospital, Birmingham

NICK ROSE

\title{
Diary from Sri Lanka's east coast: arrival
}

\begin{abstract}
A 9-year-old girl with large moist eyes stares past the doctor. She had been admitted to a district hospital with fever the morning the tsunami struck. Many patients, nurses and doctors died there, and the girl still has night terrors. The doctor interviewing her lost a number of colleagues and was traumatised himself.

Eighteen months on, the tsunami is woven into many of the stories I hear as I supervise medical officers in their psychiatric assessment work. It's hard for me to imagine what these reminders, repeated in varying forms day in
\end{abstract}

day out, mean for the health staff involved, what buttons they press. We're interrupted by the bleep of the doctor's mobile. The text message reads 'Four shootings, please go to mortuary'. Another incident in what has become a relentless trickle. The BBC World Service talks of Sri Lanka being on the brink of civil war. Three communities brace themselves, Tamils, Moslems and Sinhalese, all fearful of a descent into past horrors.

Since late April when a female suicide bomber almost killed the head of the army at the Colombo headquarters, 
tension between the communities has been palpable. I had just arrived to work for the International Medical Corps (IMC) for 3 months, supporting mental health training of public health staff in tsunami-affected areas. Then the bomb went off. Travel to the east coast was immediately frozen and everyone waited for the feared ethnic backlash. In the event, although there were air strikes, there was no civil unrest. But the trickle of incidents involving government forces and the Liberation Tigers of Tamil Eelam (LTTE) moved to a higher gear. By the time I finally made it to the tsunami area a week later, clinics and training sessions were being regularly cancelled because of security concerns.

In Batticaloa, a dream of a town set among tropical lagoons and sandbanks half way down the east coast, mortar fire wakes me in the morning, and shootings and a claymore bomb claim local victims during my seminar with medical officers. These doctors are a dedicated lot, mostly with strong links to the area, who keep the well established preventative public healthcare system going Traditionally this has meant antenatal and school health checks, immunisation programmes and an assortment of public health initiatives. However, after discussions between the Health Department of the Sri Lankan Government, the World Health Organization and the IMC, a strategy had been agreed whereby the IMC would train public health staff in primary care level psychiatric case detection and treatment. This was felt to be much needed in the tsunami-affected areas because of the level of mental health problems coming to light, particularly depression, suicide and alcoholism. Existing specialist psychiatric services were severely overstretched, and it was felt they could best be supported by grafting a psychiatric role onto the existing well-developed public health structure.

Travelling to clinics along the coast road, I pass mile upon mile of blown-out buildings, fields of rubble, washed-out causeways, temporary bailey bridges, and neat estates of picture-book dwellings funded by non-governmental organisations (NGOs). Hoardings signpost microfinance, money for work, and agricultural NGO schemes. Shining new white Landcruisers with UN agency or NGO stickers cruise the highways, giving an unintended signal of difference and power to passers-by. I'm actually rather pleased that my organisation uses modest thrashed out Toyota saloons to get about; it reduces the distance between me and the local health staff I'm working with. My Hero Indian 'standard' bicycle also helps, but mainly because people can't believe their eyes; why would anyone want to go to work on a bike if they had the use of a car! A great icebreaker and important metaphor rolled into one.

So, how can I make a difference in a 3-month attachment? I will need to keep my eye on the ball: support, train and supervise those who have a long-term stake in the east coast, who will be there long after I go; foster ways of working between health staff that are seen to benefit patients and will have some chance of enduring; spot any major unmet needs; and be cautious about seeing everything through a post-trauma Western lens. Bipolar illness, schizophrenia and major depression still need managing whatever the situation. Although a few may need focused post-trauma work, restoring normal community life through schools, work, homes and meeting places is arguably the most-effective posttrauma intervention, and this thankfully is work well in hand. However, there is still much to do. At the start of 2006, of the 850000 people displaced by the tsunami, 500000 were still living in temporary or semi-permanent shelters (World Health Organization, 2006).

As I finish writing, news comes in of a landmine explosion in Wilpattu National Park, with seven local tourists killed. One of them is Nihal De Silva, a famous Sri Lankan novelist. I have just finished reading his first novel The Road From Elephant Pass, which won the Gratiaen Literary Prize in 2003. A Romeo and Juliet story of doomed love between an LTTE cadre and a Sinhalese army officer. De Silva is reported in the press as having died with a group of Sinhalese and Tamil friends. Not a good omen for a peaceful outcome to the present tensions.

\section{Declaration of interest}

N.R. is currently on an attachment to the IMC (http:// www.imcworldwide.org/index.shtml) from his post as consultant psychiatrist and honorary senior lecturer, Oxfordshire and Bucks Mental Healthcare Trust.

\section{Reference}

WORLD HEALTH ORGANIZATION

(2006) WHO Country Cooperation

Socialist Republic of Sri Lanka. Sri Strategy 2006-2011: The Democratic Lanka: World Health Organization Country Office for Sri Lanka.

Nick Rose International Medical Corps, c/o Royal College of Psychiatrists, 17 Belgrave Square, London SW1 8PG, e-mail: pb@rcpsych.ac.uk 